(1834), "That one must have an ear for roaring is self-evident," still holds good. Anyone who is not well acquainted with the physiological dyspnœa and the wheezing respiratory sound determined by it, which is produced in sound horses after exertion continued until general outbreak of perspiration, may fall into a diagnostic error. The respiratory sounds produced during severe exertion in horses that are already in a state of perspiration over the whole body are not in all cases alike, this being due partly to voluntary habit, partly to the good or inferior constitution of the horses, partly also to the relative volume of the respiratory organs. The existence of roaring can be assumed only when a loud or hard laryngeal sound is distinguishable during inspiration. For the detection of the defect in its slightest degree it is necessary that the horse should be exercised on soft sandy ground or in a field, and not amid noisy surroundings, as otherwise the abnormal inspiratory laryngeal sound may easily escape recognition.

\title{
THE OPERATION OF THE PLEURO-PNEUMONIA ACT *
}

\author{
By Thomas Walley, M.R.C.V.S., Principal of the Royal \\ Veterinary College, Edinburgh.
}

AT first sight it may seem humiliating to have to confess that notwithstanding the length of time that pleuro-pneumonia has existed in this and continental countries we are still in the dark as to its true nature, and that the only radical measure of suppression that can be devised is one of extermination. In this matter, however, we are not in a worse position than the members of the medical profession in dealing with similar maladies of the human subject. Certainly they do not advocate the slaughter of the victims of such diseases, but they have not discovered any radical method of dealing with them, in evidence of which one may point to the continued prevalence of scarlatina, measles, whooping-cough, etc. These diseases are as much a medical opprobrium as pleuro-pneumonia is a veterinary opprobrium, both as regards their nature and the means of suppressing them.

In the early days of my acquaintance with pleuro-pneumonia, and for long afterwards, no attempt whatever was made to arrest the ravages of the disease.

It is to the unchecked progress of this malady during such a long term of years that we are indebted for the failure that has befallen our recent attempts at suppression. The measures hitherto initiated for the suppression of pleuro-pneumonia in this country have, to say the least, been "patch-work" measures, and peddling in their character. The bull has never been taken by the horns, and that is to some extent true even of the measures now in force. In matters of this kind legislation proceeds at a leaden pace.

The first suppressive measures adopted in Great Britain were the slaughter of actually diseased animals, and the segregation of those that had been in contact for the short period of 28 days.

By the slow process of evolution we went through the intermediate stage of 56 days' segregation, and finally arrived at slaughter, both of the diseased animals and of those that had been in contact with them. 
These measures, however, proved to be heavy burdens on the ratepayers in particular districts, and, in consequence, an almost universal demand was made that the measures should be made more stringent, that they should be carried out by the central authority, and that the incidence of taxation should be imperial and not local.

Now that the changes advocated have become accomplished facts, some persons have set their minds to the task of throwing opposition in the way of the accomplishment of the objects aimed at, because the orders issued for the purpose do not meet with their approval.

The only fault that the members of the profession could legitimately find with the manner of procedure adopted in carrying out the Pleuro-pneumonia Act is, that the Minister of Agriculture or his veterinary advisers did not arrange for a conference of those veterinary surgeons who had been acting as inspectors to Local Authorities and to the Board of Agriculture all over the country, but even this oversight was largely atoned for by the calling together of the representatives of Local Authorities by Mr Chaplin ; and although the members of the profession who attended the Conference were few in number, it is to be presumed that the representatives of these Local Authorities present were conversant with the views of the veterinary surgeons who had acted for them in the past.

That the measures put in force in the new Pleuro-pneumonia Orders are perfect, I am not prepared to say, but where they are found to be defective they will doubtless be improved as experience may suggest.

It has been said that some details of the Orders are derogatory to the dignity of the members of the veterinary profession, notably that which makes it incumbent on the local veterinary inspector to forward the lungs to the Board of Agriculture.

Now, personally I yield to no man living in respect of knowledge of the general clinical characters of pleuro-pneumonia or of the macroscopic characters of its lesions, but I cannot see that there is anything degrading to me in the Board requiring that I shall send the lungs of an animal to London as a proof that the post-mortem has confirmed my diagnosis or that the clinical symptoms during life were not in accordance with the conditions revealed after death. Even if my views as to the nature of the existing lesions were not in very exceptional cases in accordance with those entertained by the advisers of the Board, the fact of their disagreeing with me would not alter my opinion of the case one iota, and even if subsequent events showed that my opinion was the correct one, that would not do away with the fact that the responsibility must rest with the central authorities.

I have already said that the Orders at present in force may require to be amended in accordance with the teaching of experience, and I may venture to point out on what lines such emendations will require to proceed in order that they may prove effectual.

In this country no sanitary laws of any importance affecting the animal population exist. Animals may die and be buried without the nature of the maladies from which they have suffered being made known. No system of registration is in operation, and there is no inspection except that connected with dairies, nor is there any system of compulsory notification in force. Some time ago I expressed satisfaction that the new Order established such a system, but it would 
appear that my interpretation of one of the clauses of the Order was incorrect. That however does not alter my views as to the necessity of initiating such a system.

If a law were passed whereby the owners of animals that had either succumbed to disease or injury, or that had been slaughtered while suffering from the effects of disease, were compelled to give notice of such deaths to a responsible official, who would be charged with the duty of seeing that a post-mortem examination was made by a competent veterinary surgeon, it would be almost impossible for the existence of contagious maladies to remain undiscovered. The veterinary surgeon would, of course, have to be paid for his services by the Government, and he should be required to keep an official register of the cases dealt with by him.

It is a remarkable fact that in this, the greatest cattle-breeding country in the world, there is no system of registration except in the case of pure-bred stock.

Such a general system would be of great value in tracing disease to its source. It is so far satisfactory that a movement to secure the registration of animals exposed for sale at auction marts and markets has been set on foot, but it is to be hoped that the system will go further and be extended to all animals in farms or in dairies.

While it would perhaps be too much to suggest that an universal system of inspection should be adopted, it would not be an insurmountable task to carry out a system of rigid inspection in all infected districts, or in districts suspected of being infected. Such a system was carried out in the case of cattle plague, and there can be no doubt that it was largely instrumental in effecting the suppression of that malady.

As to compulsory notification of the existence of disease, it would perhaps be thought by some to be too great a task to undertake with reference to all diseases, but there can be no difference of opinion as to the necessity for it in the case of infected districts and in dairies.

Hitherto the veterinary surgeon in most cases has had but little to do with the valuing of diseased animals, and it has only been in exceptional cases that he has been called upon to perform the duties of an inspector of meat. In the new Orders he has to arrange for the valuation of diseased or suspected animals, and after slaughter he alone is the judge as to the fitness or otherwise of the flesh for human food, and with reference to the last point his duties extend to these animals of the herd that are apparently healthy. In view of the fact that the inspector is freed from the responsibility of adding to the rates by the condemnation of carcases, it is perfectly clear that a much larger proportion of unwholesome food will be withdrawn from consumption than has ever been the case before, and while the authorities leave it to him to use some discretion in the carrying out of his duties, the veterinary surgeon may feel quite assured that it is not the wish of the Government to become vendors of flesh that is in any degree unwholesome.

This Order for the first time places veterinary surgeons in this country in the position of inspectors of meat, and I think I may say for the whole body of the profession that, while the duties imposed upon it in this respect will be carried out with strict impartiality, no 
flesh of an unwholesome or doubtful character will be allowed to escape destruction.

Since the Pleuro-pneumonia Act came into operation there has been apparently an enormous increase in the number of cases of the disease. It is obvious that there formerly existed a large number of unreported and undiscovered centres of disease, and from these there has been a continual dispersion of diseased animals over the country. The Board of Agriculture is showing great energy in tracing out these hidden sources of infection, and when such are discovered not only the animals on the premises but also, as far as they can be traced, all animals recently sold from such premises are being slaughtered.

The action of the United States Government in placing veterinary inspectors of their own at British ports at which American cattle may be landed, has excited a good deal of comment. I recently had the good fortune to meet one of the representatives of the American Government, and to learn from him the motives which had prompted this step. The American Senate has for some time past laid aside the sum of one million dollars annually for the purpose of suppressing pleuro-pneumonia, and their efforts in this direction have been so successful that pleuro-pneumonia is now known to exist in only a very limited portion of the country. When the official returns from this country, showing that pleuro-pneumonia had been detected among American cattle landed at our ports, reached the United States authorities, it was at once concluded that the disease had an existence in one or more unknown centres, and measures were immediately adopted for the discovery of these centres.

Every animal arriving in this country from the United States in the future will not only be registered, but it will also have a tag in one of its ears to admit of future identification, and in the event of a case of pleuro-pneumonia being discovered in any of these animals the United States Inspector at the port of landing will have to at once report the occurrence, and to transmit the mark carried by the animal to the central authorities in the United States, so as to enable them to trace the animal to its original home.

This action on the part of the United States Government is, I think, much to be commended, and it must tend to inspire the stock-owners of this country with confidence, as showing the sincerity of the efforts that are being made to root pleuro-pneumonia out of American soil.

The carrying out of the Pleuro-pneumonia Act has brought to light some valuable information regarding the prevalence of tuberculosis among dairy stock in this country. The proportion of cows found to be tuberculous in some outbreaks has been, from a public health point of view, truly alarming; but a detailed statement regarding these cases must be left for another occasion.

\section{THE OCCURRENCE OF TUMOURS IN THE DOMESTICATED ANIMALS.}

\section{By J. M‘FAdyean, M.B., B.Sc., F.R.S.E., Royal Neterinary College,} Edinburgh.

(Continued from page 249.)

Tumour XXXV. Lymphosarcoma from Vagina of Bitch. - This tumour was removed with the ecraseur from the vagina of an aged 